\title{
Pesquisas com os Cotidianos: devir-filosofia e devir-arte na ciência
}

Maria da Conceição Silva Soares' 'Universidade do Estado do Rio de Janeiro (UERJ), Rio de Janeiro/RJ - Brasil

RESUMO - Pesquisas com os Cotidianos: devir-filosofia e devir-arte na ciência. Com este texto, proponho que a tendência em pesquisas que vêm se afirmando no Brasil como pesquisas nos/dos/com os cotidianos configura o atravessamento do devir-filosofia e do devir-arte na ciência da Educação. Com esse propósito, traço um caminho de pensamento que consiste em uma articulação entre ideias defendidas por Deleuze e Guattari sobre filosofia, ciência e arte e os pressupostos epistemológicos, teóricos e metodológicos defendidos por pesquisadores que se filiam a essa tendência. Por fim, indico que as pesquisas nos/dos/com os cotidianos problematizam a pureza das linguagens científica, filosófica e artística historicamente construída, transbordando as fronteiras estipuladas entre esses três modos de pensar o mundo.

Palavras-chave: Cotidianos. Fabulações. Redes. Devires. Possíveis.

ABSTRACT - Researching Daily Life: becoming-philosophy and becoming-art in science. In this text I argue that the trend in research being consolidated in Brazil as research on/of/with daily life shows the crossing of becoming-philosophy and becoming-art upon education science. With this purpose, I lay out a path for reflection consisting of an articulation of ideas defended by Deleuze and Guattari on philosophy, science, and art and epistemological, theoretical, and methodological assumptions supported by researchers involved with that trend. Finally, I indicate that research on/ of/with daily life problematizes the historically constructed purity of scientific, philosophical, and artistic languages, overflowing agreed frontiers between the three modes of thinking about the world.

Keywords: Daily Life. Fabulations. Networks. Becomings. Possibles.

Educação \& Realidade, Porto Alegre, v. 38, n. 3, p. 731-745, jul./set. 2013.

Disponível em: <http://www.ufrgs.br/edu_realidade> 
Pesquisas com os Cotidianos

Escrever a n, n-1, escrever por intermédio de slogans: faça rizoma e não raiz, nunca plante! Não semeie, pique! Não seja uno nem múltiplo, seja multiplicidades! Faça linha e nunca ponto! A velocidade transforma o ponto em linha! Seja rápido mesmo parado! Linha de chance, jogo de cintura, linha de fuga. Nunca suscite um General em você! Nunca ideias justas, justo uma ideia (Godard). Tenha ideias curtas. Faça mapas, nunca fotos nem desenhos (Deleuze; Guattari, 1995, p. 36).

Nunca ideias justas, justo uma ideia. A frase de Godard, tomada de empréstimo por Deleuze e Guattari, anuncia, de antemão, o que pretendo com esse texto: busco desenvolver justo uma ideia. E ter uma ideia, como disse Deleuze em uma palestra a estudantes de cinema1, "[...] é algo que acontece raramente, é uma espécie de festa, pouco corrente" (Deleuze apud Stassun, 2009, p. 1). Essa ideia que tive, para muitos, é ousada. Com isso, assumo, desde já, os riscos das errâncias que, por conta desse atrevimento, posso incorrer.

$\mathrm{O}$ que pretendo ao propor que as pesquisas nos/dos/com os cotidianos configuram o atravessamento do devir-filosofia e do devir-arte na ciência da Educação? Ora, busco, a partir de uma conversa com as ideias de Deleuze em filosofia (muitas das quais desenvolvidas em parceira com Guattari) repensar, problematizar e expandir possibilidades teóricas, epistemológicas, metodológicas e políticas virtuais e/ou já praticadas por diversos pesquisadores que vêm conformando essa tendência de pesquisa em Educação, à qual me filiei há pouco mais de dez anos.

Portanto, essa é uma ideia em ciência e não algo genérico, pois, concordando com Deleuze, admito que as ideias, assim como aqueles que as têm, estão destinadas a um determinado domínio e, por isso, devem ser tratadas "[...] como potenciais já empenhados nesse ou naquele modo de expressão" (Deleuze apud Stassun, 2009, p. 1). Temos, então, ideias em arte, ideias em filosofia, ideias em ciência, conforme as técnicas que conhecemos e em consonância com as maneiras pelas quais, cotidianamente, praticamos e criamos outros modos possíveis de fazer no contexto de nossos ofícios.

Dessa forma, o que desejo com esse ensaio não é fazer ponto, muito menos ponto final, mas traçar linhas, inclusive linhas de erres (aqui já assumindo o agenciamento, também nesse texto, de Certeau) ${ }^{2}$, tensionando e experimentando ressonâncias possíveis das picadas deleuzianas nos modos clássicos, para não dizer tradicionais ou hegemônicos na ciência moderna, de se fazer pesquisa em ciências sociais e humanas. Algumas dessas picadas ferem. Outras já encontram abertas as feridas produzidas pelas próprias pesquisas nos/dos/com os cotidianos em Educação.

É importante, contudo, destacar que a complexidade que foi chamada no Ocidente de modernidade é forjada em condições variadas de produção de conhecimentos, que se tecem com possíveis fragmentos de

732 Educação \& Realidade, Porto Alegre, v. 38, n. 3, p. 731-745, jul./set. 2013

Disponível em: <http://www.ufrgs.br/edu_realidade> 
saberes, práticas, lendas, narrativas, crenças, imagens, sensibilidades e memórias pertencentes, segundo Focault (2005), ao arquivo fabricado num determinado momento e recebido desde a Antiguidade. Por arquivo, o autor entende o conjunto de discursos efetivamente pronunciados e que funciona e se transforma através da história, possibilitando o surgimento de outros discursos.

Se o saber medieval acolhia, simultaneamente e no mesmo plano, magia e erudição (Foucault, 2005), o temor ao caos, o desejo de extirpar o erro, a procura da certeza e a necessidade de garantias se constituíram nas emoções básicas sobre as quais, segundo Najmanovich, se construiu o pensamento cartesiano. Para ela, o esforço racional e metódico é o que deve ser exigido e levado em conta para produção no Ocidente de um novo homem que não se deixa enganar por suas ilusões. E essa produção não foi levada a cabo de uma hora para outra, nem, apesar de sua pretensão, universalizou-se por todo o planeta. Nessa longa produção da modernidade, as Luzes constituíram um acontecimento, ou um conjunto de acontecimentos, que, segundo Foucault, determinou, pelo menos em parte, o que somos, pensamos e fazemos hoje.

A tendência em pesquisa no campo da Educação que vem, há mais de 20 anos, se constituindo e se afirmando no Brasil com essa denominação é, originalmente, tributária da obra do pensador francês Michel de Certeau. As ideias de Certeau foram apropriadas e trabalhadas, inicialmente, no pensamento educacional brasileiro dentro dos grupos de pesquisa de Nilda Alves e Regina Leite Garcia. Desde então, vêm multiplicando-se os pesquisadores que se reconhecem, diversificam e expandem essa corrente fazendo-a fluir e fruir, com maior concentração na Universidade do Estado do Rio de Janeiro, na Universidade Federal Fluminense e na Universidade Federal do Espírito Santo, mas disseminando-a também em outras instituições por todo o país. O foco desses pesquisadores está no exame das práticas cotidianas, das operações de praticantes (Certeau, 1994) que são engendradas em meio às redes de conhecimentos e significações, ou seja, às redes educativas dentrofor ${ }^{3}$ das escolas, ao mesmo tempo em que as engendram, tecendo permanentemente o social, o político, o econômico, o cultural, o tecnológico, e também, é claro, os processos educativos e curriculares.

Por outro lado, outra tendência de pesquisa em Educação, que se concentra principalmente nas universidades localizadas no Rio Grande do Sul, mas não só, filia-se ao pós-estruturalismo e é tributária, inicialmente, do pensamento de Michel Foucault, abarcando também as obras de Gilles Deleuze, Félix Guattari e Jacques Derrida. O foco dessa tendência está na compreensão dos processos de subjetivação desencadeados com os dispositivos da disciplinarização e da normalização (Foucault, 1987) e com as novas tecnologias de poder na sociedade de controle (Deleuze, 1992) em suas relações com a Educação, as escolas e os currículos, bem como com os processos de resistência e as linhas de fuga que afirmam a intransitividade da liberdade. 
Pesquisas com os Cotidianos

Diversos posicionamentos políticos, epistemológicos, teóricos e metodológicos (embora saiba que não é possível separar tudo isso) aproximam e distanciam os dois grupos. Em minhas andanças interinstitucionais tenho presenciado debates e trabalhos acadêmicos que, de alguma forma, buscam marcar esse distanciamento ou, ao contrário, buscam promover aproximações. Táticas de praticantes para escapar e sobreviver ao que é posto e imposto criando outros possíveis e linhas de fuga são a mesma coisa? Redes e rizomas têm as mesmas propriedades? Pesquisas nos/dos/com os cotidianos e cartografias se realizam da mesma forma? Dito isso, gostaria de afirmar que marcar as diferenças ou apontar similitudes não é o propósito deste texto, ainda que considere que, em comum, os dois grupos têm uma proposta de inconformismo diante do que é tido como dado, de insubmissão a todo tipo de controle que despotencializa a vida e o conhecimento e a busca por valorizar e legitimar os espaçostempos de liberdade e criação de outros modos de existência que emergem em meio às contingências da vida cotidiana $\mathrm{e}$ aos acontecimentos imprevisíveis e incontroláveis.

Como pesquisadora nos/dos/com os cotidianos, leitora também de Deleuze, me interessa, nesse momento, os modos pelos quais as ideias desse autor são operativas para nossas pesquisas. Os conceitos, já dizia o próprio Deleuze, têm valor não pela verdade que portam, mas se são úteis, se são operativos para o pensamento: “[...] nós só procuramos a verdade quando estamos determinados a fazê-lo em função de uma situação concreta, quando sofremos uma espécie de violência que nos leva a essa busca" (2003, p. 14). Em um conceito, não é a verdade (como correspondência com o objeto) que importa, mas o interesse e a novidade da proposição. Além disso, pensando com esse autor, na perspectiva antidialética o esforço consiste não em produzir sínteses, antagonismos ou consensos, mas em vislumbrar somente multiplicidades, heterogêneses, que se engendram nos espaçostempos do meio. A lógica da antidialética é, segundo Deleuze e Guattari, a lógica do E, uma pragmática que eles explicam a partir da imagem do rizoma.

\begin{abstract}
Um rizoma não começa nem conclui, ele se encontra sempre no meio, entre as coisas, inter-ser, intermezzo. A árvore é filiação, mas o rizoma é aliança, unicamente aliança. A árvore impõe o verbo 'ser', mas o rizoma tem como tecido a conjunção ‘e... e... e...' Há nessa conjunção força suficiente para sacudir e desenraizar o verbo ser. Para onde você vai? De onde você vem? Aonde quer chegar? São questões inúteis. Fazer tábula rasa, partir ou repartir do zero, buscar um começo, ou um fundamento, implicam uma falsa concepção da viagem e do movimento (metódico, pedagógico, iniciático, simbólico...) (Deleuze; Guattari, 1995, p. 37).
\end{abstract}

É o intermezzo que me interessa e, para instaurar a lógica do E, precisamos reverter a ontologia, destituir o fundamento, anular o fim e o começo. O espaçotempo intermezzo, o meio, o entre as coisas designa 
não um movimento de uma coisa em direção a outra e vice-versa, mas sim um movimento transversal que as carrega uma e outra. Com a antidialética e a lógica do E, Deleuze e Guattari procuram afirmar as multiplicidades, mostrar que elas ultrapassam as distinções concernentes à lógica binária.

Assim, sentindo-me autorizada por Deleuze, vou roubar seus conceitos à sua moda, em que roubar conceitos é produzir conceitos novos, ou ainda criar novos usos para eles, como buscamos fazer. Faço-o chegando-lhe pelas costas e fazendo-lhe um filho monstruoso, conforme, nas palavras do próprio Deleuze, teria feito Nietzsche em seus encontros com outros pensamentos e/ou pensadores.

Filhos pelas costas é ele quem faz. Ele dá um gosto perverso (que nem Marx nem Freud jamais deram a ninguém, ao contrário): o gosto para cada um dizer coisas simples em nome próprio, de falar por afectos, intensidades, experiências, experimentações. Dizer algo em nome próprio é muito curioso, pois não é em absoluto quando nos tomamos por um eu, por uma pessoa ou um sujeito que falamos em nosso nome. Ao contrário, um indivíduo adquire um verdadeiro nome próprio ao cabo do mais severo exercício de despersonalização, quando se abre às multiplicidades que $\mathrm{o}$ atravessam de ponta a ponta, às intensidades que o percorrem. O nome como apreensão instantânea de uma tal multiplicidade intensiva é o oposto da despersonalização operada pela história da filosofia, uma despersonalização de amor e não de submissão. Falamos do fundo daquilo que não sabemos, do fundo de nosso próprio subdesenvolvimento. Tornamo-nos um conjunto de singularidades soltas, de nomes, sobrenomes, unhas, animais, pequenos acontecimentos: ao contrário de uma vedete (Deleuze, 1992, p. 15).

Deleuze e seus pensamentos são, no meu entendimento, multiplicidades, atravessamentos, intensidades, que não se propõem a semear, mas picam. Operam como uma espécie de violência que, segundo esse autor, consiste no impulso para todo pensamento e para todo o conhecimento. Deleuze foi, ele próprio, um acontecimento, um agenciamento, uma atitude, que potencializou e potencializa outros pensamentos e pensadores em práticas e performances diversas e nômades, em desterritorializações, errâncias, deslocamentos e derivas, na busca da criação de outros e novos mapas de conhecimento.

Feitas as considerações que entendo como necessárias, vamos ao pensamento de Deleuze sobre o que é a Filosofia e a Arte, e às apropriações que faço em nome próprio para pensar, tensionar, expandir e afirmar as multiplicidades nas pesquisas nos/dos/com os cotidianos.

Educação \& Realidade, Porto Alegre, v. 38, n. 3, p. 731-745, jul./set. 2013. 


\section{O que é a Filosofia? O que seria o Devir-Filosofia na Ciência?}

Há uma coisa que me parece certa: um filósofo não é uma pessoa que contempla e também não é alguém que reflete. Um filósofo é alguém que cria. Só que ele cria um tipo de coisa muito especial, ele cria conceitos. Os conceitos não nascem prontos, não andam pelo céu, não são estrelas, não são contemplados. É preciso criá-los, fabricá-los (Deleuze, 2005, comunicação oral).

A definição sobre o que faz, mais do que sobre o que é, um filósofo foi dada por Deleuze em entrevista concedida a jornalista Claire Parnet para a série Abecedário de Gilles Deleuze $e^{4}$ Da exibição e discussão sobre as entrevistas que compõem a série no grupo de pesquisa do qual participo $^{5}$ emergiu o pretexto para a escritura desse texto, embora não me limite a elas. O fazer filosófico relevante e criativo, e, portanto, o devir-filosofia, estaria, segundo o autor, irremediavelmente relacionado à criação de conceitos, que, por sua vez, são indissociáveis da criação de problemas que produzam sentido. É por isso que o pensamento filosófico se difere da opinião e da comunicação. Ao invés de voltar-se para a recognição, a filosofia cria, simultaneamente, conceitos e problemas em determinado campo de imanência, no qual o conceito tem uma operacionalidade: possibilitar ou até, quem sabe, coinstituir o próprio pensamento e a solução dos problemas criados. O pensamento filosófico, dessa forma, evolui com a evolução dos problemas. Assim, prossegue Deleuze em outro trecho da entrevista:

O último aspecto dessa longa questão seria, é evidente: bem, mas o que é a evolução dos problemas? O que a assegura? Posso sempre dizer: forças históricas, sociais. Sim, claro, mas há algo mais profundo. É misterioso. E não teríamos tempo, mas creio em uma espécie de devir do pensamento, de evolução do pensamento que faz com que não apenas não coloquemos os mesmos problemas, mas com que não os coloquemos do mesmo modo. Um problema pode ser colocado de vários modos sucessivos, e há um apelo urgente, como uma grande corrente de ar, que faz apelo à necessidade de sempre criar, recriar novos conceitos. Há uma história do pensamento que não se reduz à influência sociológica ou... Há um devir do pensamento, que é algo misterioso, que seria preciso definir, que faz com que, talvez, não se pense hoje da mesma maneira que há cem anos (Deleuze, 2005, comunicação oral).

E o que esse modo de operação, que visa procedimentos para a compreensão e expressão das experimentações do mundo, implica, especialmente se evocarmos o rigor do método científico conformado e tornado hegemônico com a ciência moderna? Nas palavras de Deleuze:

Percebe-se que a filosofia nada tem a ver com o verdadeiro e o falso. A filosofia não é procurar a verdade. Procurar a 
verdade não quer dizer nada. Trata-se de criar conceitos, o que isso quer dizer? E constituir um problema? Não se trata de verdade ou falsidade, trata-se de sentido! Um problema tem de ter um sentido. Há problemas que não têm sentido, outros que o têm. Fazer filosofia é constituir problemas que têm um sentido e criar os conceitos que nos fazem avançar na compreensão e na solução do problema (Deleuze, 2005, comunicação oral).

Se parássemos aqui teríamos, sem muitos problemas, concordando ou não, uma compreensão do que quero propor ao sugerir que as pesquisas nos/dos/com os cotidianos configuram o atravessamento do devir-filosofia na ciência da Educação. Buscamos, com o exame das práticas, conforme propôs Certeau (1994), pensar outramente o social e, aí incluída, a Educação, de modo diferenciado do que se vinha fazendo há bem mais de cem anos. Não apenas não colocamos os mesmos problemas, como não os colocamos do mesmo modo. Da mesma forma que criamos novos problemas, ou os colocamos de outros modos, criamos conceitos, ainda que prefiramos falar em expressões (mas que são para nós também operativas ao nosso pensamento), juntado palavras que normalmente são grifadas em separado para poder pensar e expressar as problematizações que criamos e/ou os problemas que colocamos de outra forma.

Assim como, para Deleuze, a filosofia nada tem a ver com o verdadeiro e o falso, para nós, os efeitos que buscamos produzir com nossas pesquisas também não o têm. Não buscamos com o exame das práticas educativas concretas, e com as problematizações que criamos ao examiná-las, reconstituir e universalizar por generalização a significação ou a verdade última dos fatos, mas, sim, produzir outras possibilidades e sentidos, afirmativos e expansivos, que impulsionem a constituição permanente dos praticantes da cultura (Certeau, 1994) e a reinvenção dos contextos cotidianos em que vivemos. É nesse sentido que a função fabuladora desencadeada com as narrativas, verbais e imagéticas, em suas multiplicidades, atravessamentos e heterogêneses, é imprescindível às nossas pesquisas.

Contudo, Deleuze e Guattari (1992, p. 156) diferenciam a abordagem da ciência da abordagem filosófica diante do caos que caracteriza o mundo. A filosofia, segundo ele, procura dar consistência (aos conceitos que ela cria) sem nada perder do infinito. O problema dela é diferente do da ciência, que procura dar referências ao caos, sob a condição de renunciar aos movimentos e velocidades infinitos, e de operar, desde o início, uma limitação de velocidade, uma desaceleração. Enquanto a filosofia tem por objeto criar conceitos (e para isso traça um plano de imanência que lhes dê suporte e personagens conceituais que os formulem), a ciência tem por objeto apresentar funções ou preposições (e para isso cria um plano de referência e observadores parciais), que lhe permita refletir e comunicar. É por meio do plano de referência que a ciência recorta e limita o caos. 
Pesquisas com os Cotidianos

Dir-se-ia que a ciência e a filosofia seguem duas vias opostas, porque os conceitos filosóficos têm por consistência acontecimentos, ao passo que as funções científicas têm por referência estados de coisas ou misturas; a filosofia não para de extrair, por conceitos, do estado das coisas um acontecimento consistente, de algum modo um sorriso sem gato, ao passo que a ciência não cessa de atualizar, por funções, o acontecimento num estado de coisas, uma coisa ou um corpo referíveis (Deleuze; Guattari, 1992, p. 164).

Deleuze e Guattari, ao realizarem essa análise, consideram os procedimentos das ditas ciências duras, naturais e exatas. Ainda assim, eles defendem que há criação tanto na filosofia como na ciência e destacam que a criação não existe sem a experiência ou um vivido, independente das diferenças que apontaram entre a linguagem filosófica e a linguagem científica. Além disso, para eles, multiplicidades científicas (discursivas, extensionistas) e filosóficas (intuitivas e intensivas) colaboram e inspiram-se mutuamente. Deleuze e Guattari (1992), por fim, admitem que não é impossível que um conceito filosófico seja usado cientificamente e que ambos os modos de compreensão do mundo podem se atravessar eventualmente. Numa indagação, que é ao mesmo tempo uma provocação, eles sinalizam: "É o mesmo que perguntar se a ciência, como acreditamos, precisa da filosofia. Mas só os cientistas estão aptos a responder esta questão" (Deleuze; Guattari, 1992, p. 192).

A partir dessa compreensão e dos modos pelos quais se realizam as abordagens nos/dos/com os cotidianos, considerando a criação, a desterritorialização e a ressignificação de conceitos, a formulação de personagens conceituais, as problematizações criadas, a emersão no movimento e no caos, e suas multiplicidades também intuitivas e intensivas, é que propomos que em essas nossas pesquisas admitimos e desejamos o atravessamento do devir-filosofia na ciência da Educação. Ainda que, como cientistas, nos ocupemos do vivido ou dos estados de coisas que povoam nossos campos de referência, evocamos a filosofia e também a arte para, do modo como nos é possível, não perder de vista o acontecimento e a criação do porvir.

\section{O que é Arte? O que Seria o Devir-Arte na Ciência?}

Como se ocupar do vivido sem deixar de atentar para o que excede os significados produzidos e comunicados, individualmente (em nome próprio?), por aqueles que o experimentam na sua concretude cotidiana, de modo a subverter a opinião (que se molda sobre a recognição) e a representação na perspectiva clássica? Em outras palavras, o que nos move em nossas percepções e afetações em meio às relações que estabelecemos no/com o mundo? Para pensar essa problematização, pode nos ser útil a compreensão que Deleuze e Guattari têm da arte e dos seus modos operacionais. Para eles: 
A arte é a linguagem das sensações, que faz entrar nas palavras, nas cores, nos sons ou nas pedras. A arte desfaz a tríplice organização das percepções, afecções e opiniões, que substitui por um monumento composto de perceptos, de afectos e de blocos de sensações que fazem as vezes de linguagem (Deleuze; Guattari, 1992, p. 208).

Segundo esses autores, se os cientistas traçam planos de referência, formulam observadores parciais, introduzem variáveis e criam proposições e funções, e se os filósofos traçam planos de imanência, formulam personagens conceituais, introduzem variações e criam conceitos, os artistas traçam planos de composições, formulam figuras estéticas, introduzem variedades e criam blocos de sensações, perceptos e afectos.

Os artistas, assim, arrancam o percepto das percepções, o afecto das afecções, a sensação da opinião, visando o que ainda não existe. Para compreender essa proposta, é necessário entender o que são, para eles, percepções e afetações e o que são perceptos e afectos.

Percepção e afetação resultam das interações dos corpos que condicionam sensibilidades.

O que se chama 'percepção' não é mais um estado de coisas, mas um estado do corpo enquanto induzido por outro corpo, e 'afecção' é a passagem deste estado a um outro, como aumento ou diminuição do potencial-potência, sob a ação de outros corpos: nenhum é passivo, mas tudo interação [...] (Deleuze; Guattari, 1992, p. 183, grifos do autor ).

Isso vale para pessoas e coisas, já que "[...] as coisas têm um vivido, porque são percepções e afecções” (Deleuze; Guattari, 1992, p. 183). Já os perceptos não são percepções, são frutos da criação e ganham vida própria, independente daqueles que os experimentam (tanto o criador como o expectador). Os afectos também não são afecções, nem sentimentos, e transbordam a força daqueles que são atravessados por eles. A obra de arte, assim compreendida, é um ser que existe por si mesmo e excede qualquer vivido conservando blocos de sensação compostos por perceptos e afectos. Perceptos e afectos, portanto, seriam produtos do fazer artístico que transcendem ao próprio criador "[...] pela autoposição do criado, que se conserva em si” (Deleuze; Guattari, 1992, p. 193). A sensação não se realiza no material necessário à produção da obra, embora sua conservação dependa dele. Para esses autores, toda a matéria se torna expressiva. Seria a sensação, como um modo de expressar o mundo que se conserva, independente da experiência vivida, do criador e do público (expectador, leitor, ouvinte etc.) um atributo apenas da obra de arte? Como se cria um bloco de sensações? Como se extrai perceptos e afectos de percepções e afecções? Conforme Deleuze e Guattari, para se criar uma obra de arte não basta a memória do vivido, do experimentado, que convoque somente antigas percepções, mas é preciso por em ato a fabulação. 
A memória intervém pouco na arte (mesmo e sobretudo em Proust). É verdade que toda obra de arte é um monumento, mas o monumento não é aqui o que comemora um passado, é um bloco de sensações presentes que só devem a si mesmas sua própria conservação, e dão ao acontecimento o composto que o celebra. O ato do monumento não é memória, mas a fabulação (Deleuze; Guattari, 1992, p. 198).

Nessa perspectiva, nada é, tudo se torna. Tudo é devir. Não somos, não estamos no mundo, mas nos tornamos com o mundo, completando-o.

A função fabuladora criadora nada tem a ver com uma lembrança mesmo amplificada, nem com um fantasma. Com efeito, o artista, entre eles o romancista, excede os estados perceptivos e as passagens afetivas do vivido. É um vidente, alguém que se torna. Como contaria ele o que lhe aconteceu, ou o que imagina, já que é uma sombra? Ele viu na vida algo muito grande, demasiado intolerável também, e a luta da vida com o que a ameaça, de modo que o pedaço da natureza que ele percebe, ou os bairros da cidade, e seus personagens, acedem a uma visão que compõe, através deles, perceptos dessa vida, deste momento, fazendo estourar as percepções vividas numa espécie de cubismo, de simultantismo, de luz crua ou de crepúsculo, de púrpura ou de azul, que não têm mais outro objeto nem sujeito senão eles mesmos (Deleuze; Guattari, 1992, p. 202).

Os perceptos dão às paisagens e aos personagens dimensões que a percepção vivida não pode atingir. Assim, toda fabulação é, para Deleuze e Guattari, uma fabricação de gigantes.

Do mesmo modo que o percepto ultrapassa a percepção, o afecto ultrapassa a afecção, o sentimento, e é o devir não humano dos homens, algo que passa por ele, que o atravessa, e que só pode estar presente como sensação, produzindo uma zona de indeterminação, como se coisas e pessoas tivessem atingido um ponto infinito que precede sua indiferenciação. Enfim, um afecto é um devir. Enquanto que o artista é “[...] mostrador de afectos, inventor de afectos, criador de afectos, em relação com os perceptos ou as visões que dá a ver" (Deleuze; Guattari, 1992, p. 207).

Como o modo operacional da composição artística pode atravessar o da referência científica modificando-a, sem que uma se torne a outra? A mim interessa, principalmente, a função fabuladora da arte e a possibilidade de criar e expressar conhecimentos também como blocos de sensações, compostos por perceptos e afectos. É o que buscamos com nossas narrativas dos cotidianos.

\section{Como Fazer da Ciência uma Obra de Arte que não Tente Deter o Movimento nem Aprisionar o Infinito?}

Trata-se, então, não de criar obras de arte, mas de fazer da ciência uma obra de arte, um discurso potencializado por uma função fabuladora que ultrapasse, embora reconheça, o que existe. Uma ciência que 
crie, também, com palavras e imagens, sensações, perceptos, afectos, devires. Que para além da cognição e recognição, seja capaz de impulsionar a criação de mundos possíveis. Um modo de fazer ciência comprometido com a sobrevivência e com o vivido, mas que os ultrapassa em busca da expansão e da afirmação da vida. Um modo de fazer ciência que institua a vontade de poder, de potência, de invenção, e o querer sempre mais como sinal de força, saúde, direito e vida. Para todos.

De acordo com Deleuze e Guattari (1992, p. 81) “[...] o plano de composição da arte e o plano de imanência da filosofia podem deslizar um no outro, a tal ponto que certas extensões de um sejam ocupadas por entidades do outro". O mesmo poderia acontecer entre um e outro e o plano de referência da ciência? Aposto que sim.

São portanto interferências extrínsecas, porque cada disciplina permanece sobre seu próprio plano e utiliza seus elementos próprios. Mas um segundo tipo de interferência é intrínseco, quando conceitos e personagens conceituais parecem sair do plano de imanência que lhes corresponderia, para escorregar sobre um outro plano, entre as funções e os observadores parciais, entre as sensações e as figuras estéticas; e o meso vale para outros casos (Deleuze; Guattari, 1992, p. 256).

Dessa forma, considero, com Alves (2010), as imagens, figurativas ou não (conforme o código empregado e a intenção do autor), como personagens conceituais ${ }^{6}$ em nossas produções. Nós, pesquisadores nos/ dos/com os cotidianos, consideramos inclusive as imagens técnicas fotografias e vídeos, por exemplo - indispensáveis ao desenvolvimento do nosso pensamento, mesmo sabendo que para Deleuze e Guattari as imagens técnicas, ao contrário das artísticas (figuras estéticas), operam como um decalque, o qual eles definem da seguinte forma:

Ele é antes uma como uma foto, um rádio que começaria por eleger ou isolar o que ele tem a intenção de reproduzir, com a ajuda de meios artificiais, com a ajuda de colorantes, ou outros procedimentos de coação. É sempre o imitador quem cria seu modelo e o atrai. O decalque já traduziu o mapa em imagem, já transformou o rizoma em raízes e radículas. Organizou, estabilizou, neutralizou as multiplicidades segundo eixos de significância e de subjetivação que são seus (Deleuze; Guattari, 1995, p. 23).

Mas, como eles próprios sugerem, não podemos projetar decalques sobre mapas? Não podemos quebrar a hegemonia da significação, como em uma “[...] mais-valia de código, aumento de valência, verdadeiro devir” (Deleuze; Guattari, 1995, p. 19)? Não podemos arrancar as imagens de seus territórios, desterritorializá-las e reterritorializá-las com outros enunciados, independente das intenções do autor e dos contextos de significação, de representação?

Educação \& Realidade, Porto Alegre, v. 38, n. 3, p. 731-745, jul./set. 2013. 
Pesquisas com os Cotidianos

Em nossas pesquisas, as imagens operam como possibilidades, impulsos, violências para a fabulação, para a produção de novos enunciados e novos desejos. Como na obra de Foucault, conforme a análise de Certeau (2002), em nossas pesquisas as imagens instituem textos. É nesse sentido que pouco importa se elas se propõem a ser figurativas ou não, pois entendemos que imagens potencializam pensamentos para além dos que elas pretendem dar a ver. Elas emanam perceptos e afectos, devires, como acontece com o punctum de Barthes (2006), um elemento, um pequeno acaso, que salta da cena e transpassa nosso corpo como uma flecha provocando uma ferida.

Contudo, como para nós as imagens remetem a narrativas e viceversa, a função fabuladora desencadeada com as imagens, implica, como sugerem Gonçalves e Head (2009), o devir-imagético dos próprios pesquisadores e dos demais praticantes com os quais realizamos as pesquisas nos/com os cotidianos, quando nos pomos a ficcionar. Assim, o devirimagético ao qual nos referimos não é o devir da imagem (em si), mas o devir de todos nós, engendrado quando nos pomos a imaginar, a ficcionar sobre os outros, sobre o vivido e sobre nós mesmos, nos reinventando e reinventando o mundo. Segundo Gonçalves e Head (2009, p. 29):

Nesse sentido, a criação do devir-imagético via fabulação é justamente 'monstruosa' no sentido que ganha vida própria através da conjunção de fatores pessoais e impessoais tais quais as tecnologias, as instituições, os acontecimentos e produtos do 'acaso'.

Embora recorramos à memória, ao criar e ao entrar em relação com narrativas verbais e imagéticas, não a concebemos como restituição, resgate ou reconstrução do passado, mas como fabulação de um passado nas contingências de um presente. Memória, assim compreendida, como fabulação que reconfigura passado e presente, acionada por perceptos e afectos, tomando de assalto espaçostempos vividos e/ou outros inexistentes para instituir outros possíveis.

Ainda assim resta uma questão: como interpretamos acontecimentos, fenômenos e narrativas (verbais e imagéticas)? O que fazemos é fenomenologia, tão fortemente criticada por Deleuze e Guattari? Para alguns seria, inclusive, para alguns outros a própria obra de Deleuze seria fenomenológica. Mas, no meu entendimento, esse é um falso problema, como diria Deleuze. A verdadeira provocação que esta questão coloca estaria na ideia de interpretação efetuada por um sujeito como interioridade isolável capaz de encarnar, carregar e desvelar um fenômeno, um acontecimento, uma sensação, ao invés de ser arrastado, modificado, transformado por tudo isso. Com efeito, não é assim que compreendemos o modo pelo qual vemos, ouvimos, lemos, sentimos. Fazemos tudo isso com nossas redes, como afirma Alves (2010). Esse nossas redes, na minha compreensão, abarca memórias transindividuais, fabulações coletivas, repertórios imagéticos e linguísticos, agenciamentos e tudo mais que se produz nos encontros e atravessamentos entre coisas, pessoas, animais, perceptos, afectos e devires.

742 Educação \& Realidade, Porto Alegre, v. 38, n. 3, p. 731-745, jul./set. 2013 Disponível em: <http://www.ufrgs.br/edu_realidade> 
Não fazemos filosofia. Não fazemos arte. Fazemos ciência. Fazemos pesquisas nos/dos/com os cotidianos. Ao fazê-las e ao comunicarmos os achados de nossas criações, buscamos problematizar a pureza dos procedimentos e da linguagem científicos historicamente construídos, transbordando as fronteiras estipuladas entre esses modos de pensar o mundo. Com Deleuze e Guattari compartilhamos que:

Há enfim interferências ilocalizáveis. É que cada disciplina está, à sua maneira, em relação com um negativo: mesmo a ciência está em relação com uma não-ciência que lhe devolve seus efeitos. Não se trata somente de dizer que a arte deve nos formar, nos despertar, nos ensinar e sentir, nós que não somos artistas - e a filosofia ensinarnos a conceber e a ciência a conhecer. Tais pedagogias só são possíveis, se cada uma das disciplinas, por sua conta, está numa relação essencial com o Não que a ela concerne (1992, p. 256)

E os autores, vão além. Embora as disciplinas precisem de seus negativos, no plano cerebral, a cada instante de seu próprio devir e desenvolvimento, esse foradentro é, praticamente, indiscernível no mundo da vida.

Ora, se os três Não se distinguem ainda pela relação com o plano cerebral, não mais se distinguem pela relação com o caos no qual o cérebro mergulha. Neste mergulho, diríamos que se extrai do caos a sombra do 'povo por vir', tal como a arte o invoca, mas também a filosofia, a ciência: povo-massa, povo-mundo, povo-cérebro, povo-caos. Pensamento não-pensante que se esconde nos três, como conceito não conceitual de Klee ou o silêncio interior de Kandinsky. É aí que os conceitos, as sensações, as funções se tornam indecidíveis, ao mesmo tempo que a filosofia, a arte e a ciência, indiscerníveis, como se partilhassem a mesma sombra, que se estende através de sua natureza diferente e não cessa de acompanhá-los (Deleuze; Guattari, 1992, p. 257).

Com Certeau (1994), compreendemos que as maneiras de fazer constituem processos mudos de apropriação que organizam a ordenação sociopolítica e instauram um presente relativo a um determinado espaçotempo, estabelecendo contato com outro numa rede de relações. Essas astúcias compõem, no limite, a rede de uma antidisciplina no espaçotempo organizado pelas técnicas de produção sociocultural. Entendemos, então, que as pesquisas nos/dos/com os cotidianos implicam decisões epistemológicas e políticas, constituem um movimento antidisciplinador dos saberesfazeres e caracterizam uma atitude em favor do pensamento alargado e da vida ativa.

Nossas comunicações científicas, atravessadas por devires (devirfilosofia e devir-arte, entre tantos outros não abordados aqui), constituem narrativas híbridas que sobrepõem elementos descritivos, exten- 
sivos, intuitivos e intensivos, além de sensações, perceptos e afectos, para criar e experimentar o porvir. Afinal, como dizia o próprio Deleuze “[...] a ciência seria completamente louca se a deixassem agir" (1995, p. 36). Talvez, porque o devir-ciência deva ser um devir-revolucionário, como todos os devires.

Recebido em 2 de setembro de 2011 Aprovado em 28 de junho de 2012

\section{Notas}

1 Palestra proferida em Paris, em 1987, transcrita e publicada na internet com o título $O$ ato de criação, acessada em dezembro de 2009.

2 "Produtores desconhecidos, poetas de seus negócios, inventores de trilhas nas selvas da racionalidade funcionalista, os consumidores produzem uma coisa que se assemelha às linhas de erre de que fala Deligny. Traçam trajetórias indeterminadas, aparentemente desprovidas de sentido por que não são coerentes com o espaço construído, escrito e pré-fabricado onde se movimentam" (Certeau, 1994, p. 97).

3 Nas pesquisas nos/dos/com os cotidianos, esse modo de escrever esses termos tem a ver com a necessidade que sentimos em mostrar os limites herdados dos modos de criar conhecimentos, hegemônicos na ciência moderna, que consideravam as dicotomias necessárias à produção do conhecimento científico.

4 As entrevistas para série Abecedário de Gilles Deleuze foram concedidas à jornalista Claire Parnet em 1988-1989 e exibidas na TV Arte (canal franco-alemão) entre novembro de 1994 e maio de 1995. São mais de sete horas de gravação. Os vídeos podem ser acessados no YouTube e as transcrições estão disponíveis em vários sites na internet. Uma delas foi acessada por mim em 2005.

5 Grupo de Pesquisa Currículos, Redes Educativas e Imagens, coordenado pela professora Nilda Alves do Programa de Pós-Graduação em Educação - UERJ.

6 Deleuze e Guattari (1992, p. 209) admitem que, embora não sejam idênticos, figuras estéticas e personagens conceituais podem entrar uns nos outros, como o Zaratrusta de Nietzsche.

\section{Referências}

ALVES, Nilda. Dois Fotógrafos e Imagens de Crianças e seus Professores as Possibilidades de Contribuição de Fotografias e Narrativas na Compreensão de Espaçostempos de Processos Curriculares. In: OLIVEIRA, Inês Barbosa de (Org.). Narrativas: outros conhecimentos, outras formas de expressão. 1. ed. Petrópolis/RJ: DPetAlii, 2010. P. 185-206.

BARTHES, Roland. A Câmara Clara: nota sobre a fotografia. Tradução de Manuela Torres. Lisboa: Edições 70, 2006.

CERTEAU, Michel de. A Invenção do Cotidiano: 1. Artes de Fazer. Tradução de Ephraim Ferreira Alves. Petrópolis, RJ: Vozes, 1994.

CERTEAU, Michel de. Histoire et Psychanalyse: entre science et fiction. Paris: Folio Histoire, 2002.

DELEUZE, Gilles. Abecedário de Gilles Deleuze. Entrevista concedida a Claire Parnet. Disponível em: <http://desobediente.multiply.com/journal/item/6>. Acesso em: 27 jul. 2005.

744 Educação \& Realidade, Porto Alegre, v. 38, n. 3, p. 731-745, jul./set. 2013 Disponível em: <http://www.ufrgs.br/edu_realidade> 
DELEUZE, Gilles. Conversações. Tradução de Peter Pál Pelbart. Rio de Janeiro: Ed. 34, 1992a.

DELEUZE, Gilles. O que é a Filosofia? Tradução de Bento Prado Jr. e Alberto Alonso Muñoz. Rio de Janeiro: Ed. 34, 1992b.

DELEUZE, Gilles; GUATTARI, Félix. Mil Platôs: capitalismo e esquizofrenia. Tradução de Aurélio Guerra Neto e Celia Pinto Costa. São Paulo: Ed. 34, 1995. Volume 1.

DELEUZE, Gilles. Proust e os Signos. Tradução de Antonio Carlos Piquet e Roberto Machado. Rio de Janeiro: Forense Universitária, 2003.

FOUCAULT, Michel. Arqueologia das Ciências e História dos Sistemas de Pensamento: ditos \& escritos II. Seleção e Organização de Textos: Mantel Barros da Motta. Rio de Janeiro: Forense Universitária, 2005.

FOUCAULT, Michel. Vigiar e Punir: nascimento da prisão. Tradução de Raquel Ramalhete. Petrópolis, RJ: Vozes, 1987.

GONCALVES, Marco Antonio; HEAD, Scott. Confabulações da Alteridade: imagens dos outros (e) de si mesmos. In: GONÇALVES, Marco Antonio; HEAD, Scott (Org.). Devires Imagéticos: a etnografia, o outro e suas imagens. Rio de Janeiro: 7Letras, 2009. P. 15-35.

NAJMANOVICH, Denise. O Sujeito Encarnado: questões para pesquisa no/do cotidiano. Rio de Janeiro: DP\&A, 2001.

STASSUN, Cristian. O Ato de Criação por Gilles Deleuze. Especial para a Trafic. Tradução: José Marcos Macedo. Folha de São Paulo, São Paulo, 27 jun. 1999. Disponível em: <http://cristianccss.wordpress.com/2007/09/19/o-ato-de-criacao-por-gilles-deleuze/>. Acesso em: 02 dez. 2009.

Maria da Conceição Silva Soares é professora adjunta da Universidade do Estado do Rio de Janeiro - UERJ, atuando na Faculdade de Educação e no Programa de Pós-Graduação em Educação - ProPEd, na Linha de Pesquisa Cotidianos, Redes Educativas e Processos Culturais. É coordenadora do Grupo de Pesquisa Currículos, Narrativas Audiovisuais e Diferença. Tem artigos, capítulos de livros e livros publicados, voltados para diferentes questões referentes às pesquisas com os cotidianos das redes educativas. E-mail: ceicavix@gmail.com 